\title{
Learning Open Science by doing Open Science. A reflection of a qualitative research project-based seminar.
}

Isabel Steinhardt (corresponding author)

International Centre of Higher Education Research (INCHER) Kassel, University of Kassel

Mönchebergstr. 17, 34109 Kassel, Germany, +49 561 8042892, steinhardt@incher.uni-kassel.de

\begin{abstract}
Openness in science and education is increasing in importance within the digital knowledge society. So far, less attention has been paid to teaching Open Science in bachelor's degrees or in qualitative methods. Therefore, the aim of this article is to use a seminar example to explore what Open Science practices can be taught in qualitative research and how digital tools can be involved. The seminar focused on the following practices: Open data practices, the practice of using the free and open source tool "Collaborative online Interpretation, the practice of participating, cooperating, collaborating and contributing through participatory technologies and in social (based) networks. To learn Open Science practices, the students were involved in a qualitative research project about "Use of digital technologies for the study and habitus of students". The study shows the practices of Open Data are easy to teach, whereas the use of free and open source tools and participatory technologies for collaboration, participation, cooperation and contribution is more difficult. In addition, a cultural shift would have to take place within German universities to promote Open Science practices in general.
\end{abstract}

\section{Keywords}

Open Science, Open Education, Digital Practices, Habitus, Digital Technologies 


\section{Introduction}

Openness in science and education is becoming more important in the digital knowledge society. Openness is discussed in a number of different ways: in research, under the heading Open Science (OS) and in teaching under the headings Open Education (OE) and Open Pedagogy. OS is also an umbrella term (Fecher \& Friesike, 2014) incorporating various concepts. For more clarity, the EUfunded FOSTER Plus project (Facilitate Open Science Training for European Research) created a taxonomy defining OS. This taxonomy includes the following: Open Access means free access to scientific results, Open Data comprises the online provision of research data collected in research projects, which is made freely available for re-use. Open reproducible research is an OS practice enabling the independent reproducibility of research results. Open Science Evaluation includes Open Peer Review as well as Altmetrics or Bibliometrics. Open Science Tools refers on the one hand to software that can be accessed online free of charge and on the other hand open to platforms for workflow and repositories (Pontika, Knoth, Cancellieri, \& Pearce, 2015). The aspects listed in the taxonomy cover the entire research process from data generation to the evaluation of the research results by the scientific community.

Along with OS, there is also an OE Movement. As Weller (2018) explains, OE is strongly influenced by the Open Education Resources (OER) movement and the 5Rs. The 5Rs are Reuse, Revise, Remix, Redistribute and Retain (Weller, 2018). Similar to OS, OE is a broad concept that can be interpreted from a narrow use and re-use of OER to a much broader understanding as OE practices (Bellinger \& Mayrberger, 2019). OE practices "include the creation, use, and reuse of open educational resources (OER) as well as open pedagogies and open sharing of teaching practices (Cronin, 2017). As Weller (2018, p. 57) further explains, some principles are central to OE: "freedom to reuse; open access; free cost; easy use; digital, networked content; social, community-based approaches; ethical arguments for openness; and openness as an efficient model". In accordance with Open Pedagogy, also central are: "participatory technologies and social networks for interaction, peer-learning, knowledge creation, and empowerment of learners" (Cronin, 2017, p. 4). 
In an attempt to combine OS practices of research with practices and principles of the OE practices of teaching in higher education, I developed a project-based seminar concept and generated an OS tool (KolloIn: Collaborative online interpretation). I tested both in a university course in sociology in Germany. The seminar was integrated into the author's qualitative research project "Use of digital technologies for the study and habitus of students“, using the habitus-hermeneutic (Bremer \& TeiwesKügler, 2014). A project-based learning setting was used. This setting was selected because including students in research projects leads to a deeper understanding of the methods and the research process (Healey, 2005). This goes hand in hand with an understanding of learning as a process, one that takes time and can be accompanied by a change in practices. Learning is also ,not something done to students, but rather something students themselves do" (Ambrose, Bridges, DiPietro, Lovett, \& Norman, 2010, p. 3).

Open digital research practices are not yet widespread, particularly in qualitative research (Steinhardt 2018). Therefore, the aim of this article is to use a seminar example to explore which OS practices can be taught in qualitative research and how digital tools can be involved.

To answer these questions, three levels are considered. The first consideration is the structure of the seminar and the Open Source tool KolloIn. Secondly, it will be discussed what offers are needed to teach OS practices and how students accept OS/OE practices as well as which insights were gained into basic principles and the practical handling of OS. Thirdly, the level of the research project will be considered. This level reflects which research-related theoretical and empirical findings can be drawn on the habitus and use of digital technologies.

The following chapter distils OS practices from the literature that is already used in teaching and combines them with OE practices to form characteristics of OS/OE. I then go on to describe the research project of which the project-based seminar was part. The next section focuses on the seminar concept details. In the fifth chapter, I use the characteristics of OS/OE developed in chapter two to describe the taught practices. Finally, I discuss the experiences of the seminar and give some ideas for further development of teaching OS practices in a digital world. 


\section{Teaching Open Science - state of the art}

As Steinhardt (2019) illustrates, teaching OS and involving students in OS projects is not an extensively discussed topic. However, one exception is the involvement of students in replication studies (Chopik, Bremner, Defever, \& Keller, 2018; Janz, 2016). Replication of research and the reuse of data in connection with the replication crisis is discussed. The term replication crisis refers to the difficulties involved in reproducing results from scientific studies (Randall \& Welser, 2018). The authors (Frank \& Saxe, 2012; Grahe et al., 2012; Hawkins et al., 2018) argue replications are timeconsuming and expensive, and "normal" researchers are often unwilling to do this task. One response to these challenges is for students to conduct replication studies with open data (Frank \& Saxe, 2012; Hawkins et al., 2018; Toelch \& Ostwald, 2018). Thereby, students could learn not only the scientific process, but also the importance of methodological standards. In addition, students could learn the value of openness (Frank \& Saxe, 2012). Frank and Saxe (2012) highlight the importance of collaboration between instructors and students both in identifying interesting experiments and in cooperating on the identified replication studies. They also mention four benefits of replication seminars: First, student motivation is higher than in normal seminars because of the possibility to contribute research results to the scientific community. Secondly, this possibility leads students to be more attentive to the process, thus methods become more concrete. Thirdly, as students need the literature for their own experiments and calculations, they tend to be more thorough in their reading. Fourthly, students experience first-hand the frustrations of poor documentation about experiments and calculations and, as a result, reflect better practices (Frank \& Saxe, 2012).

Replication studies are often dependent on access to data. Therefore, one of the central aspects of the OS movement is open data, which includes the documentation and archiving of data. These aspects are taught in data management courses (Piorun et al., 2012; Whitmire, 2015). Data management includes "to be aware of and adhere to their principal investigator's plan for the effective management, storage, and sharing of research data" (Adamick, Sheridan, \& Reznik-Zellen, 2012, p. 180). Developers of the curriculum and associated modules are mostly librarians who perceive teaching data management as a 
new task for libraries (Schmidt \& Holles, 2018). In order to reuse data, students need digital literacy skills that must be trained in the classroom (Cook, Çakirlar, Goddard, DeMuth, \& Wells, 2018).

Open Source Software (OSS) is a major topic in computer sciences (Braught et al., 2018; Faber, 2002; Nandigam, Gudivada, \& Hamou-Lhadj, 2008; O’Hara \& Kay, 2003) and in geospatial science education (Mitasova, Shukunobe, Landa, \& Kratochvilova, 2012; Osaci-Costache, Cocos, \& Cocos, 2017; Petras, Petrasova, Harmon, Meentemeyer, \& Mitasova, 2015). Petras et al. (2015, p. 943) point out, integration of free and open source software in geospatial science education is necessary "to encourage a culture of openness and, thus, enable greater reproducibility in research and development applications." For computer sciences, O'Hara and Kay recognize that: "OSS has the potential to expand group work beyond the classroom to include much larger projects and more distributed teams. OSS can also be used to introduce our students to the larger computer science community and to the practice of peer-review. Finally, OSS can often provide us with free or lower-cost technology in the classroom, permitting us to use technology that we might otherwise be unable to afford." (O'Hara \& Kay, 2003, p. 1) The use of free and open sources is also widespread in business. This gives computer science teachers the opportunity to work with realistic software systems and real code cooperating with companies (Buffardi, 2015; Carrington \& Kim, 2003; Sowe \& Stamelos, 2007). "Using open source software also has the beneficial effect of ensuring that students are aware of the open source software movement, and opens up opportunities to discuss topics such as software piracy and ethics" (Carrington \& Kim, 2003, SIC 9).

Collaboration and cooperation are important topics in OS and OE. Wikis are used in teaching to enable and promote cooperation and collaboration between students (Bruns \& Humphreys, 2005). Particular attention is paid to "collaborative and responsible learning" (Jaksch, Kepp, \& WomserHacker, 2008, p. 77) as well as cooperative learning (Schaffert \& Ebner, 2010) and the generation of open knowledge through wikis (Ebner, Kickmeier-Rust, \& Holzinger, 2008).

In summary, there are certain elements of OE that are implemented in the teaching of OS:

- Open data practices for reuse, replication, revise and archiving. Archiving also includes practices of data management. 
- The practice of using free and open source software and tools, including the discussion about usability and ethics.

- The practice of participating, cooperating, collaborating and contributing through participatory technologies and in social (based) networks especially wikis but also tools for coding and seminar communication.

- Knowledge creation and empowerment of leaners through project- or research-based seminars according to OS (including use and reuse of Open Access papers).

With respect to the second aspect of the seminar, the use of qualitative data, only a few studies could be found that address qualitative research by focusing on the sharing and re-using of qualitative data. While these studies are not project-based, they nevertheless show teachers how to use open qualitative data (Bishop, 2012; Corti \& Bishop, 2005; Kretzer, 2013). However, little is known about how a qualitative project-based OS seminar could look like and how OE practices could be integrated. Therefore, I will present the seminar structure using the list above as an analytical framework to analyse the seminar. Before discussing the seminar, I briefly describe the project the seminar was part of.

\section{The Research Project "Use of digital technologies for the study and}

\section{habitus of students"}

The project-based seminar was part of the author's research project "Use of digital technologies for the study and habitus of students". The findings from the project on the use of digital technologies by students are also relevant to the seminar. They explain why the change of practices is difficult and time-consuming. Germany is a latecomer with regard to the use of digital technologies in teaching at universities. A study by Persike and Friedrich (2016) assumes that students use conventional media more often because teachers introduce conventional media in their courses. Furthermore, teachers do not provide guidance on how to independently search and find other digital learning materials.

However, these instructions are necessary as, despite what is commonly believed, digital natives or a net generation do not exist (Kennedy et al. 2008; Rowlands et al. 2008; Kirkwood and Price 2005). 
Accordingly, students do not automatically have the skills necessary to deal competently and critically with digital technologies and Web 2.0. Rather, they show divergent practices of acquiring media competence (Schulmeister, 2009). This diverse digital literacy could lead to a second digital divide (van Deursen \& van Dijk, 2019).

The different approaches to digital technologies may be influenced by the habitus and thus lead to orientations acquired in local social contexts and class positions (Ignatow \& Robinson, 2017; Robinson, 2009; Robinson et al., 2015). According to Bourdieu's theory, the habitus represents the incorporated patterns of action, thought and perception inherited in one's own social context (Bourdieu, 1977, 1984). These patterns are based on social, cultural, symbolic and economic capital, whereby the capital is distributed differently among the social classes. Social capital describes the social relationships that someone can fall back on, while symbolic capital describes prestige and recognition in society. Cultural capital is associated, for example, with education and academic titles. Economic capital refers to the material resources available to a social subject. Due to different access to these types of capital, a class habitus is formed that manifests in the preferences and above all in the practices of people. Thus, practices are the "link between social structures and the personal way of life" (Zillien \& Marr, 2013). Therefore, how students use digital technologies may be due to their habitus, and may, as a result, reproduce existing social inequalities in higher education, or even produce new inequalities because of the second digital divide.

Based on these findings, I assumed the participants had little experience with Web 2.0 applications at the university so far. Additionally, these findings were the theoretical starting point for the students in my seminar to determine the use of digital technologies and the habitus. Therefore, the students conducted narrative interviews (Nohl, 2010) using the habitus-hermeneutics method (Bremer \& Teiwes-Kügler, 2014; Lange-Vester, 2012; Lange-Vester \& Teiwes-Kügler, 2013) to reconstruct the habitus of the interviewed students and discover if there is a connection between the habitus and the practice of using digital technologies for studying. The following sections outline the method, the interviews, and the structure of the seminar. 


\section{The seminar plan and participation}

The seminar entitled "Finding the connection between digital media and habitus with qualitative methods" (Dem Zusammenhang von digitalen Medien und Habitus qualitativ auf der Spur), was part of a BA study programme in sociology at the University of Kassel, Germany. The seminar was open to sociology students as well as for teacher training students ${ }^{1}$. It was an optional seminar. Thirteen students participated in the course - nine sociology students and four teacher training students. Nine students were female, four were male.

In the introductory session, I gave an overview of the project-based learning setting and presented the research project of which the seminar was part of. I also inquired about the students' knowledge of digital technology user practices, the habitus concept and whether they had ever collected data themselves. It transpired that only one student had heard of the concept of habitus and no one had ever collected any data. Three of the four teacher training students had prior experience with digital tools for school lessons. Nevertheless, none of the students had ever been scientifically involved with digital technology or digital usage practices.

Due to the little theoretical knowledge of the students, the first part of the seminar lessons was spent on teaching the basics of the concept of habitus and students' use of digital technologies. I tried to use open access publications such as the meta study on students' use of media (Steffens, Schmitt, \& Aßmann, 2018). In the case of the habitus theory, however, it seems that publications are not openly available online. Therefore, I uploaded these publications to the Moodle system used at the University of Kassel so students could gain online access.

The second part of the seminar focused on the interviews the students had to conduct. Based on the studies on student's use of digital technologies, the seminar group jointly developed questions for the interviews. Additionally, the students received a comprehensive introduction in conducting narrative

\footnotetext{
${ }^{1}$ In the federal state of Hesse, it is compulsory for students of teacher training to attend seminars in the fields of political science, history or sociology. The students can choose the seminar by their interests.
} 
interviews. Finally, only five students conducted an interview in order to obtain an examination. The other students, who only wanted to receive proof of attendance, took part in the course without conducting an interview.

The last part of the seminar included the interpretation of the interviews. The interpretation took place in the seminar with both an on-site group and online group. At the end of the seminar, both students and teacher gave feedback about the seminar, the online tool, and the interpretation sessions. Also, I offered an interpretation session during the semester break, to discuss questions and further interpretations for those students who wrote a seminar thesis.

\section{Learning Open Science by doing Open Science}

Here I describe the OS practices I taught to the students. To analyse and reflect on the seminar concept I will use the list of OS aspects integrated into OE developed from the literature in chapter two.

\subsection{The practices of open data}

To describe the practice of open data in the seminar presented here, it is first necessary to describe the process of conducting the interviews. As mentioned, the students conducted narrative interviews to reconstruct the practices of using digital technologies and the habitus of students. Schütze (1977), developed the narrative interviewing method in the 1970s. This method allows the reconstruction of the biography and the underlined experiences the interviewed person has. In a narrative interview, the interview persons put the made experiences into context so that the interviewer can understand them. Through these connections, the everyday practices that underlie these experiences can be reconstructed. Narrative interviews are conducted openly, i.e., no fixed guideline is used. This allows the interviewees to set their own priorities in the narrative.

As mentioned, the students had no experiences with empirical qualitative research. They did not know how to conduct an interview, nor how to identify topics they should address in the interview. To prepare the students for the interview situation and to empower them to identify topics that might be relevant for the project topic, I selected literature that points to possible connections between habitus and digital technologies. From this literature, the students were expected to identify topics themselves. 
However, a significant level of guidance was needed to establish this knowledge transfer. The topics we identified together were:

- Social background of the family and how digital technologies were used in the family.

- School time in general and if and how digital technologies were part of school.

- The peer group at school and the peer group in the university and how they use digital technologies.

- How the interviewees use digital technologies for study purposes.

In preparation for narrative interviews, we jointly developed an open introductory question in the seminar. The following is an example of how a student asked the prepared question:

"I: Yes uhh now that we have clarified the formalities, I would like to start with the interview. We had already discussed that it is about the use of digital technologies in your biography and I would now ask you to tell me your biography and how digital media appear in it. Uhhm, it's important for me to say again that you can take a long time for this. I won't interrupt you now and will take notes for any questions I may ask and you can take as much time as you want." (Interview of a student, translation by the author)

As the students were unfamiliar with conducting interviews, they were trained by using role-plays. A central part of the role-plays, was the clarifying of formalities. Since, in the spirit of OS, the aim was to re-use the interviews and to interpret them online, the interviewees first had to agree to this handling of their data and the students were informed of relevant data protection regulations. The General Data Protection Regulation (GDPR) has been in force in Germany and internationally, demanding farreaching protection of personal data. In order not to violate the GDPR, a comprehensive declaration of consent was provided, which the students used for their interviews. Furthermore, the interviewees were informed in advance of the intended further utilization of the interview material, and they could choose to give their consent to the following:

- Audio recording of the interview.

- Anonymous transcription. 
- Use of the anonymous transcript for online interpretation.

- Permission to post the anonymous transcript to a repository for re-use.

Potential interviewees could also receive additional information on the research project provided by my blog posts (https://sozmethode.hypotheses.org/278). Consciously, this should lessen the otherwise prevailing information hierarchy between interviewee and interviewer. Five students conducted an interview. They were free to choose their interview partners. All interviewees agreed that we could interpreted the interviews online and archive for re-use.

After completing the interviews, the students transcribed them by applying the "minimaltranscription" principles of the GAT2 guidelines (GAT = Gesprächsanalytisches Transkriptionssystem - Conversation Analytic transcription system) (Selting et al., 2009). In this form of transcription, the interviews are transcribed literally, i.e. there is no "smoothing" of the text, but intonations, omissions, dialects, etc. are adopted instead (https://sozmethode.hypotheses.org/339). A literal transcription, as directed by GAT, is intended to produce the most authentic picture possible of what has been said thus allowing hermeneutical interpretation.

In the seminar, the students received instructions on how to make the interviews anonymous to make them archival. Identifying all parts of the interview that allow identification of the interviewee is important, such as place of study, place of birth and names and to replace them with placeholders. I chose the "Research Data Centre for Higher Education Research and Science Studies (RDC-DZHW)" in Hannover, Germany (https://fdz.dzhw.eu/en/index_html) as a repository and discussed the decision with the students. The RDC-DZHW is specialized in data in higher education research (in Germany) and thus enables a high visibility of the data. The RDC-DZHW checked the anonymous interviews before archiving and making the data accessible. In addition, the data have received a Digital Object Identifier (DOI) making them easy to find.

The aim of employing open data practices was to teach students how to conduct an interview, which data protection guidelines exist for conducting and re-using interviews, how to transcribe and anonymise interviews so that they can be made accessible for re-use, and how the data management process works. 


\subsection{The practice of using free and open source software and tools}

To interpret the transcribed interviews we used the habitus-hermeneutics method (Bremer \& TeiwesKügler, 2013, 2014; Lange-Vester \& Teiwes-Kügler, 2013; Teiwes-Kügler \& Lange-Vester, 2018). This method aims at reconstructing the habitus and the associated practices of individuals through rule-based interpretation. The applied procedure comprises four steps: 1) the creation of an analytical protocol, 2) the conducting of a sequence analysis, 3) the analysis of the habitus based on elementary categories and 4) the formation of the habitus syndrome. Step 2 is particularly important for the analysis, as this is where the opening of the material and the interpretation take place.

Part of the seminar was to enable this step of interpretation through a free and open source tool. However, prior to the seminar such a tool did not exist for habitus hermeneutics. For this reason, we developed the online tool KolloIn (collaborative online Interpretation) ${ }^{2}$. For the development of KolloIn we used the open source Semantik DataWiki extension Objective Hermeneutic Interpreter (OHI) (Veja, Sticht, Schindler, \& Kminek, 2017), developed for objective hermeneutics (Schindler et al. 2017). OHI offers more functions than needed for the habitus hermeneutics method we were seeking. Therefore, we reduced the OHI functions for the adoption of the tool KolloIn. KolloIn has two main functions - the possibility to interpret a sequence and generate ad hoc hypotheses (Lesarten), and the option to comment on given interpretations. The second step, the commenting, was only possible when an interpretation had already been given. The following gives an overview of the new tool, providing a more detailed picture of the structure and the steps of KolloIn.

The KolloIn homepage (sozmethode.de) provides information on:

- What hermeneutic methods are and how sequence analysis work.

- How the process of collaborative online interpretation work.

- An overview of all sequences interpreted so far.

\footnotetext{
${ }^{2}$ I would like to thank Vincent Mahnke, for technical support and further development of the OHI tool, and Chris Buchheim, who set up and further developed KolloIn for me during an internship.
} 
- The research project "Use of Digital Media for Studying and Student Habitus".

- How to reuse the software.

The first line of the starting page contains a direct link to the current sequence that is to be interpreted. This link leads to the interpretation page, where users find the title of the sequence, the sequence itself, general instructions, and an overview of the transcription rules. Users are asked to read carefully the sequence line by line. The sequence analysis begins with reading the 'unit of meaning' (Schneijderberg $\&$ Steinhardt, 2019). A unit of meaning may be a part of a sentence, a sentence or several sentences. The sequence analysis aims to obtain as many interpretations as possible. All thoughts are welcome, which make the expressions within the sequence understandable and meaningful (Bremer \& TeiwesKügler 2013). The different interpretations of the sequences serve as "traces", that have to be checked, supplemented, and partly corrected in the course of further evaluation. However, more important than conclusive answers in the first interpretation are questions and hints that indicate a direction and can be followed in the further analysis (Bremer \& Teiwes-Kügler 2013: 208). A click on the link "Interpretation of the sequence" starts the actual interpretation (fig. 1).

Fig. 1: Starting page of the interpretation process at KolloIn

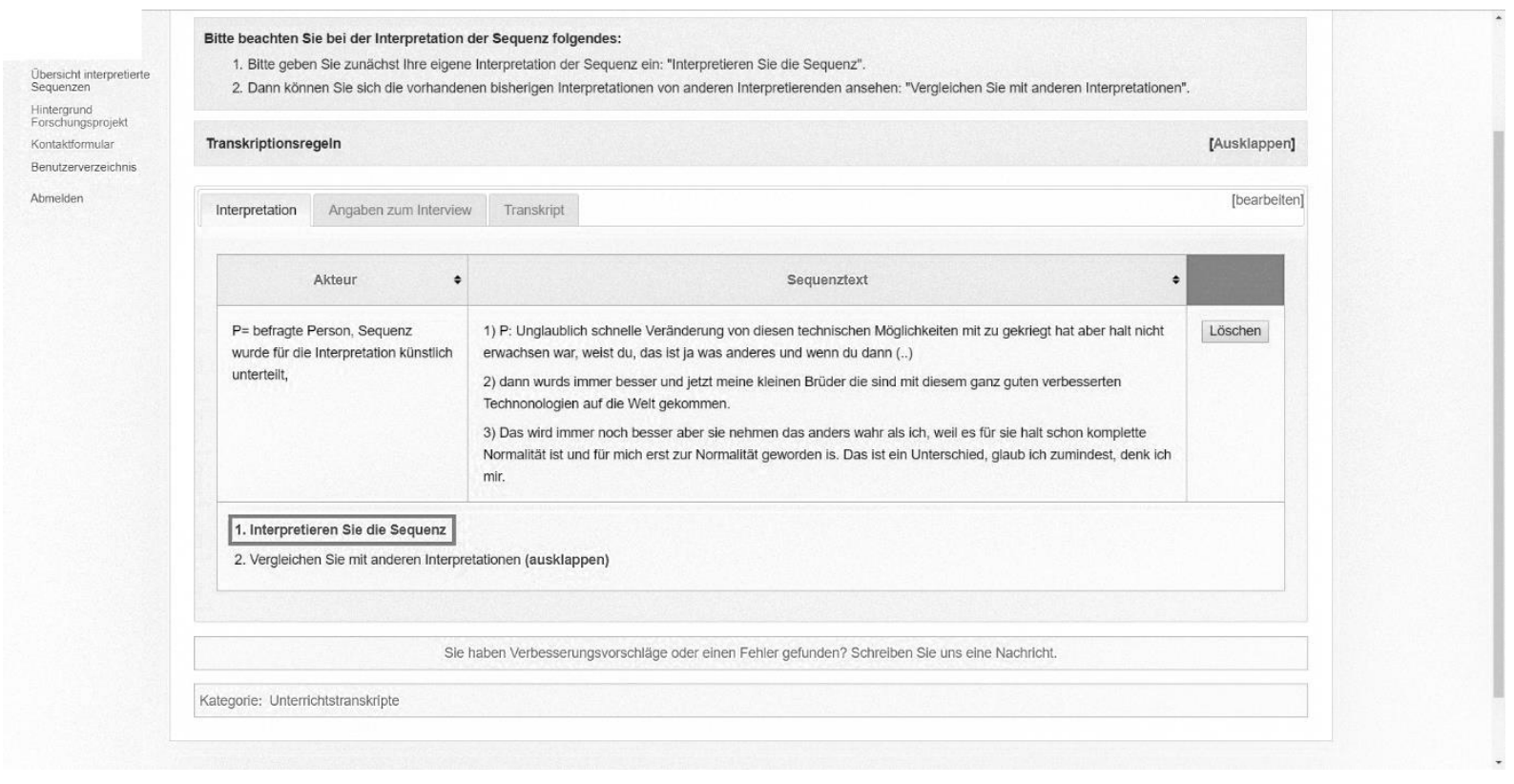

Source: www.sozmethode.de 
A click on the link "Interpretation of the Sequence" (Interpretieren Sie die Sequenz) opens the interpretation interface (fig. 2). Here, again, the user finds the sequence text with numbered lines, and an overview of the transcription rules, which if necessary, can be unfolded by clicking on them. Below the sequence text, is a text box "Line number(s)". The lines to which the interpretation refers must be inserted here. A second text box is for the interpretation of the sequence. Below the text box for the interpretation, there is another text box in which ad-hoc hypotheses can be inserted. The interpretation is completed by saving. However, the user can carry out further interpretations at any time by opening up the interpretation interface again. After saving the interpretation, the user can no longer change the interpretation. But the user can comment on the given interpretation. This restriction is important so that the original interpretation remains when the other interpretations have been read.

Fig. 2: Entering interpretation at KolloIn

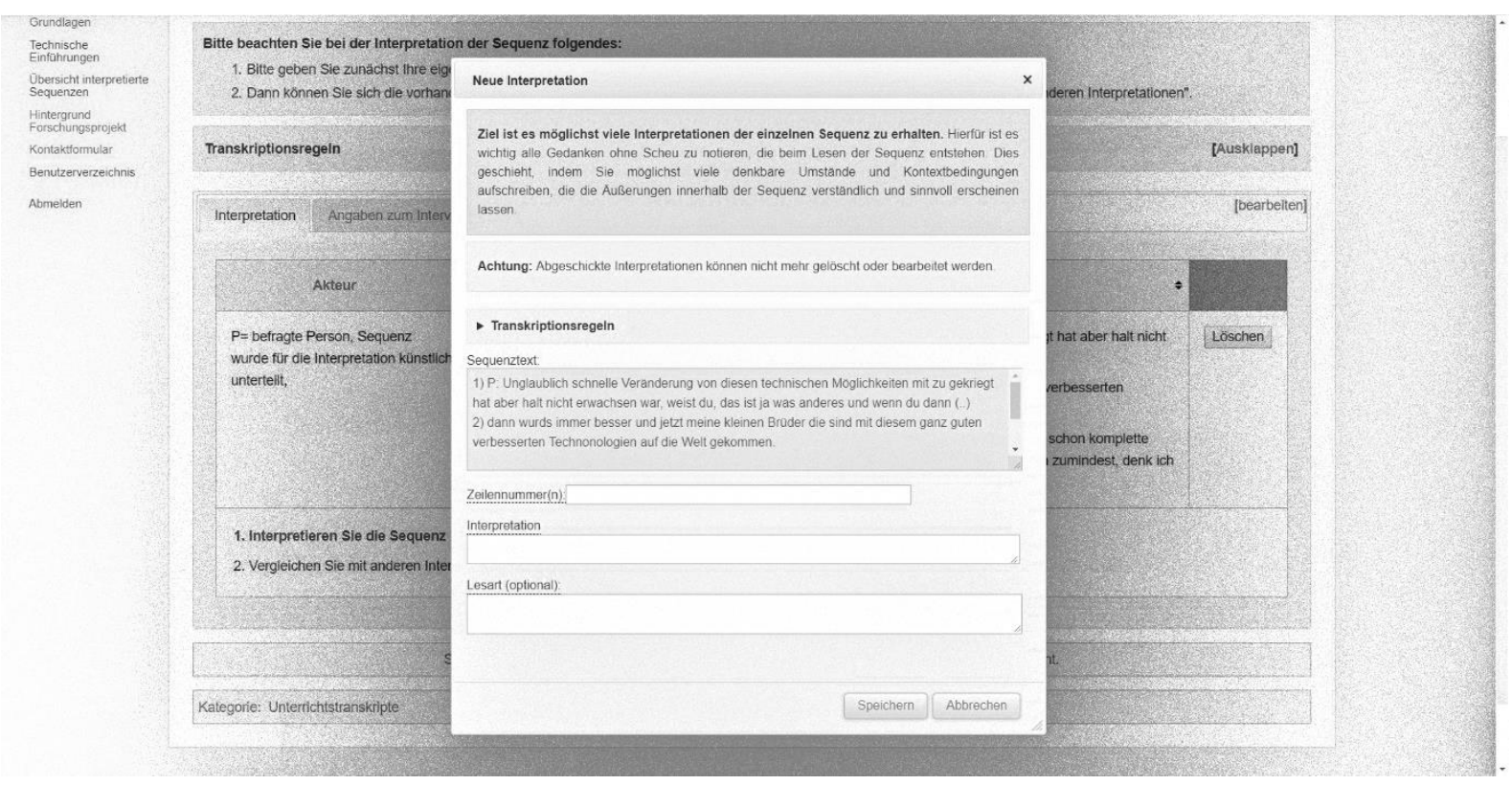

Source: www.sozmethode.de

After having saved the first interpretation, users can compare their own interpretation(s) with others. This operation can be started by clicking on the link "Compare with other interpretations" to be found right below the sequence (fig. 3 ). 
Fig. 3: Compare with other interpretations at KolloIn

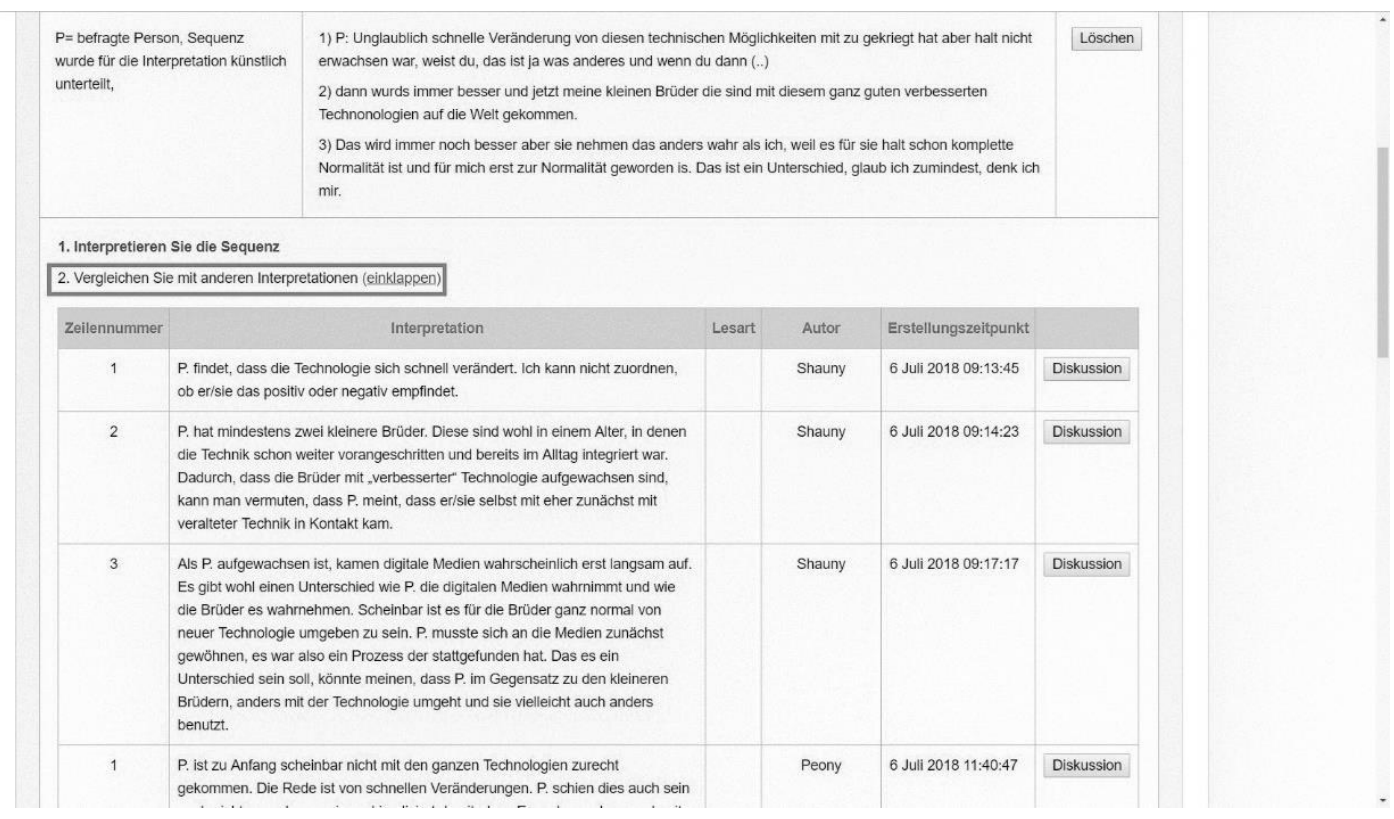

Source: www.sozmethode.de

The page "Compare with other interpretations" offers the possibility to comment on interpretations of others or to add a comment to one's own interpretation. For this purpose, users must press the "Discussion" button next to the interpretation they wish to comment upon. Then, a further text box opens, into which one can type the comment. This offers social media inspired communication and establishes a direct dialogue between users (Schmidt \& Taddicken, 2017). Therefore, all comments are immediately published without being first checked by a moderator.

The students had the choice to interpret online or in the seminar. Only five of thirteen students chose to use the online tool. For their choice of online interpretation, the students stated temporal and spatial independence and interest in a new digital tool. The other students preferred to interpret in-class because of uncertainty on how to deal with the digital tool and the openness of interpretations on the internet (even if the interpretations are anonymised) and the certainty of being able to make fewer mistakes in the seminar. These statements show that digital tools in teaching, especially when the results are put online, can lead to barriers. In this context, further options for lowering these mental barriers would have to be considered. 
The evaluative discussion with the five students showed that using KolloIn was simple. This simplicity of use was due to the Wiki-Basis, with which all students were already familiar. The descriptions and instructions were also easy to understand.

However, despite the easy to understand instructions, the students still reported difficulties in interpreting the sequences. The difficulties were caused by the uncertainty as to which interpretation was correct and by the fear of giving wrong interpretations. Measures were taken to help students to understand that all interpretations were possible and meaningful in the activity.

Unfortunately, the interaction between the students was low, i.e. they did not use the comment function. When asked why, the students answered that they found it difficult to comment on the interpretations of the others, because they did not know which interpretation was correct. This feedback shows how insecure students are about their own interpretations and how important open tools could be for learning hermeneutics.

Overall, the online interpretations of the students demonstrated an intensive examination of the sequences and a wide range of readings, some of which were wider than those of the in class interpretations. Accordingly, it seems essential to continue working on the possibility of digital online interpretations to fully exploit their potential.

In summary, I did not succeed in creating a comprehensive commitment for the project. Although the students fulfilled the course requirements, voluntary collaboration did not happen. In retrospect, it would have been wise to declare the commenting of the interpretations of others as mandatory.

\subsection{The practices of participation, cooperation, collaboration and contribution through participatory technologies and in social (based) networks}

Due to the lack of commitment, it was not possible to establish cooperation, collaboration and participation in the seminar via participatory technologies. The students interpreted the text passages via the tool KolloIn (as requested by me), but commenting on the interpretation by others did not happen. I was unable to motivate the students to use social media. At the beginning of the seminar, I tried using Twitter and the interactive functions of Moodle as a communication tool. Despite Moodle 
being the University of Kassel's well-established organisation and communication tool, the students did not take up this offer and I was unable to convince the students of the benefits of using such communication tools. To establish this form of communication in the seminar, it would have been necessary to demand communication via Twitter as a performance requirement. Furthermore, the proportion of students in Germany who use Twitter is very low, meaning students would need to learn a new tool. However, this was not the aim of the seminar, which focused primarily on research practices.

\section{Teaching Open Science Practices - a reflection}

The aim of the presented seminar was to consider which OS practices can be taught. Within a seminar, practices cannot be learned and existing practices cannot be changed; a longer time period is needed to establish or change practices (Bourdieu 1977). However, by implementing the seminar as a projectbased seminar, I hoped the basic principles of OS would reach the students and they could create knowledge and empower themselves as learners. As the above explanations show, a mixed conclusion can be drawn.

First, the students conducted, transcribed and anonymised the interviews in the sense of re-use and perceived the idea of creating open data from the material as positive. Based on conversations and observations of the students, I assume they have understood the basic principles of the practice of open data. Through their own research, students learned about data protection regulation (GDPR) and its consequences for conducting interviews. The students also learned which regulations must be fulfilled for re-use for the conducted interviews. Through their own research, the students built up competences for their own future research. Whether they will apply the open data practice in the future (for example when writing their thesis) would have to be evaluated. I can only confirm this in one case.

Second, my assumption that students are more motivated in a project-based seminar than in a normal seminar could not be confirmed (cf. for the higher motivation Frank \& Saxe, 2012). I observed how the students only worked the minimum amount (which was no more than in other seminars) and were unwilling to do any additional work. I tried to make the project results publicly accessible in other ways, e.g., through a joint blog post, or by publishing excellent term papers, but this was rejected by 
the students due to the additional work involved. My use of the seminar results for presentations and the naming of the students as project participants was perceived as positive by the students. They welcomed this form of appreciation.

Third, there was a mixed response to the use of KolloIn. On the one hand, only five of the thirteen students were willing to use the digital tool. The reasons they stated were temporal and spatial independence and interest in a new digital tool. At the same time, there was also the fear of doing something wrong and not giving correct interpretations. This fear first had to be removed thus enabling the students to work productively with the tool. Nevertheless, the tool, which is at time of writing unique, worked. This means that it can also be used in other contexts (read more about how it can be rebuilt at www.sozmethode.de). The students positively evaluated KolloIn: it was easy to use because it is a wiki and therefore the design and the application are familiar. But it is unclear whether the students learned about the underlying practice of using it as a free and open source software and what it meant e.g., with regard to ethical and economic contexts.

Fourth, students use digital technologies in their private lives, but the application of digital technologies for their studies is not common practice. This is in line with the research results from chapter three. How digital technologies can be used for learning is not taught comprehensively in schools or universities in Germany. Students do not learn the possibilities of Web 2.0 such as digital communication, collaboration and cooperation. This was also demonstrated in the seminar presented here. Although familiar with this knowledge, I was not didactically prepared to teach these practices to students.

Overall, the reflection of the seminar shows, that since the application of open practices such as digital cooperation, collaboration or participation was not mandatory, these practices were not used. The students contributed to the seminar only what was required. This is unsurprising, as digital practices and the empowerment of learners are not part of the academic habitus in sociology. In German sociology courses, digital offers are limited and the learning of digital practices even less widespread. Study programs in sociology are also characterised by small-scale memorisation or homework that focuses on a minor part of the subject. This means that a project-based seminar is often not a 
previously experienced practice and therefore uncharted territory. The benefit of extra work is therefore difficult to communicate, particularly considering the large student workload (through parttime work and study requirements). The idea that the students could be a part of knowledge production by doing science is difficult to convey as teachers typically see students as learners who cannot contribute to knowledge production, but rather, are only consumers of knowledge. Most students have adopted this view and have correspondingly a consuming attitude. This attitude is supported or determined by the curricula of the study programmes that in Germany are still predominantly teachercentred and have not (yet) completed the shift from teaching to learning. The attempt to empower learners could therefore only be implemented to a limited extent. In Germany, the shift from teaching to learning, initiated by the Bologna Process, has not yet taken place, therefore, it is difficult to teach OE practices and OS practices. Open practices aim to change the practices and to develop an open culture of interaction, collaboration and cooperation. These open practices are a retreat from (pre)lived academic practices. In order to live and teach open practices, however, the conditions at German universities would have to change and a cultural change would have to take place. Because OS practices are not conceivable without digital skills. However, digital literary is not yet a lived practice in Germany, which is why teachers must first address these skills before OS practices can be taught more comprehensively.

\section{Literature}

Ambrose, S. A., Bridges, M. W., DiPietro, M., Lovett, M. C., \& Norman, M. K. (2010). How Learning Works: Seven Research-Based Principles for Smart Teaching. John Wiley \& Sons.

Baltzersen, R. K. (2010). Radical transparency: Open access as a key concept in wiki pedagogy. Australasian Journal of Educational Technology, 26, 791-809.

Bellinger, F., \& Mayrberger, K. (2019). Systematic Literature Review zu Open Educational Practices (OEP) in der Hochschule im europäischen Forschungskontext. MedienPädagogik: Zeitschrift für Theorie und Praxis der Medienbildung, 34, 19-46.

Bourdieu, P. (1977). Outline of a theory of practice. Cambridge: Cambridge University Press.

Bourdieu, P. (1984). Distinction: A social critique of the judgment of taste. Cambridge: Harvard University Press.

Braught, G., Maccormick, J., Bowring, J., Burke, Q., Cutler, B., Goldschmidt, D., ... Tucker, A. (2018). A Multi-Institutional Perspective on H/FOSS Projects in the Computing Curriculum. ACM Transactions on Computing Education, 18, 7:1-7:31. 
Bremer, H., \& Teiwes-Kügler, C. (2013). Zur Theorie und Praxis der „Habitus-Hermeneutik“. Empirisch arbeiten mit Bourdieu: theoretische und methodische Überlegungen, Konzeptionen und Erfahrungen, 93-127.

Bremer, H., \& Teiwes-Kügler, C. (2014). Habitusanalyse als Habitus-Hermeneutik. ZQF - Zeitschrift für Qualitative Forschung, 14, 199-219.

Buffardi, K. (2015). Localized open source collaboration in software engineering education. 2015 IEEE Frontiers in Education Conference (FIE), 1-5.

Carrington, D., \& Kim, S-K. (2003). Teaching software design with open source software. 33rd Annual Frontiers in Education, 2003. FIE 2003, 3, S1C-9.

Chopik, W. J., Bremner, R. H., Defever, A. M., \& Keller, V. N. (2018). How (and Whether) to Teach Undergraduates About the Replication Crisis in Psychological Science. Teaching of Psychology, 45, 158-163.

Cook, K., Çakirlar, C., Goddard, T., DeMuth, R. C., \& Wells, J. (2018). Teaching Open Science: Published Data and Digital Literacy in Archaeology Classrooms. Advances in Archaeological Practice, 6, 144-156.

Cronin, C. (2017). Openness and Praxis: Exploring the Use of Open Educational Practices in Higher Education. The International Review of Research in Open and Distributed Learning, 18, 1-21.

Ebner, M., Kickmeier-Rust, M., \& Holzinger, A. (2008). Utilizing Wiki-Systems in higher education classes: A chance for universal access? Universal Access in the Information Society, 7, 199207.

Faber, B. D. (2002). Educational Models and Open Source: Resisting the Proprietary University. Proceedings of 20th Annual International Conference on Computer Documentation, 8. Toronto, 31-38.

Fecher, B., \& Friesike, S. (2014). Open Science: One Term, Five Schools of Thought. In S. Bartling \& S. Friesike (Eds.), Opening Science: The Evolving Guide on How the Internet is Changing Research, Collaboration and Scholarly Publishing (pp. 17-47).

Frank, M. C., \& Saxe, R. (2012). Teaching Replication. Perspectives on Psychological Science, 7, 600-604.

Grahe, J. E., Reifman, A., Hermann, A. D., Walker, M., Oleson, K. C., Nario-Redmond, M., \& Wiebe, R. P. (2012). Harnessing the Undiscovered Resource of Student Research Projects. Perspectives on Psychological Science, 7, 605-607.

Hawkins, R. X. D., Smith, E. N., Au, C., Arias, J. M., Catapano, R., Hermann, E., .. Frank, M. C. (2018). Improving the Replicability of Psychological Science through Pedagogy. Advances in Methods and Practices in Psychological Science, 1, 7-18.

Healey, M. (2005). Linking Research and Teaching to Benefit Student Learning. Journal of Geography in Higher Education, 29, 183-201.

Ignatow, G., \& Robinson, L. (2017). Pierre Bourdieu: Theorizing the digital. Information, Communication \& Society, 20, 950-966.

Jaksch, B., Kepp, S.-J., \& Womser-Hacker, C. (2008). Integration of a Wiki for Collaborative Knowledge Development in an E-Learning Context for University Teaching. In A. Holzinger (Ed.), HCI and Usability for Education and Work (pp. 77-96). Berlin Heidelberg: Springer.

Janz, N. (2016). Bringing the Gold Standard into the Classroom: Replication in University Teaching. International Studies Perspectives, 17, 392-407.

Lange-Vester, A. L. (2012). Teachers and habitus: The contribution of teachers' action to the reproduction of social inequality in school education. Revista de Sociología de La EducaciónRASE, 5, 455-476. 
Lange-Vester, A., \& Teiwes-Kügler, C. (2013). Das Konzept der Habitushermeneutik in der Milieuforschung. In A. Lenger, C. Schneickert, \& F. Schumacher (Eds.), Pierre Bourdieus Konzeption des Habitus (pp. 149-174). Wiesbaden: Springer.

Mitasova, H., Shukunobe, M., Landa, M., \& Kratochvilova, A. (2012). Building open source geospatial education at research universities. Proc. Open Source Geospatial Research \& Education Symposium (OGRS), 42-49.

Nandigam, J., Gudivada, V. N., \& Hamou-Lhadj, A. (2008). Learning software engineering principles using open source software. 2008 38th Annual Frontiers in Education Conference, S3H-18S3H-23.

O’Hara, K. J., \& Kay, J. S. (2003). Open source software and computer science education. Journal of Computing Sciences in Colleges, 18, 1-7.

Osaci-Costache, G., Cocos, O., \& Cocos, A. (2017). Geography Students' Perception Related to the Use of Gis Open Source Software in Geographic Higher Education. Romanian Review of Geographical Education, 6, 93-113.

Persike, M., \& Friedrich, J.-D. (2016). Lernen mit digitalen Medien aus Studierendenperspektive. Sonderauswertung aus dem CHE Hochschulranking für die deutschen Hochschulen. Themengruppe 'Innovationen in Lern- und Prüfungsszenarien' koordiniert vom CHE im Hochschulforum Digitalisierung. Stifterverband für die Deutsche Wissenschaft.

Petras, V., Petrasova, A., Harmon, B., Meentemeyer, R., \& Mitasova, H. (2015). Integrating Free and Open Source Solutions into Geospatial Science Education. ISPRS International Journal of Geo-Information, 4, 942-956.

Pontika, N., Knoth, P., Cancellieri, M., \& Pearce, S. (2015). Fostering open science to research using a taxonomy and an eLearning portal. Proceedings of the 15th International Conference on Knowledge Technologies and Data-Driven Business - i-KNOW '15, 1-8.

Randall, D., \& Welser, C. (2018). The irreproducibility crisis of modern science: Causes, consequences, and the road to reform (National Association of Scholars (U.S.), Ed.). Retrieved from https://www.nas.org/images/documents/irreproducibility_report/NAS_irreproducibilityReport. pdf

Robinson, L. (2009). A Taste for the Necessary. Information, Communication \& Society, 12, 488-507.

Robinson, L., Cotten, S. R., Ono, H., Quan-Haase, A., Mesch, G., Chen, W., ... Stern, M. J. (2015). Digital inequalities and why they matter. Information, Communication \& Society, 18, 569582.

Schaffert, S., \& Ebner, M. (2010). New Forms of and Tools for Cooperative Learning with Social Software in Higher Education. In B. A. Morris \& G. M. Ferguson (Eds.), Computer-Assisted Teaching: New Developments (pp. 151-165). New York: Nova Science Publishers.

Schmidt, J.-H., \& Taddicken, M. (2017). Soziale Medien: Funktionen, Praktiken, Formationen. In J.H. Schmidt \& M. Taddicken (Eds.), Handbuch Soziale Medien (pp. 23-37). Wiesbaden: Springer.

Schmidt, L., \& Holles, J. H. (2018). Teaching Research Data Management: It Takes a Team to Do It Right! Presented at the ASEE Annual Conference \& Exposition. Retrieved from https://www.asee.org/public/conferences/106/papers/21194/view.

Schneijderberg, C., \& Steinhardt, I. (2019). Accreditation of X Qualities Instead of Quality X: A Normative Analysis of Criteria of the German Higher Education Accreditation Regime. Higher Education Policy, 32, 5-28.

Schütze, F. (1977). Die Technik des narrativen Interviews in Interaktionsfeldstudien: Dargestellt an einem Projekt zur Erforschung von kommunalen Machtstrukturen. Bielefeld:

Universitätsverlag Bielefeld. 
Schulmeister, R. (2009). Studierende, Internet, E-Learning und Web 2.0. In N. Apostolopoulos, H. Hoffmann, V. Mansmann, \& A. Schwill (Eds.), E-Learning 2009: Lernen im digitalen Zeitalter (pp. 129-140). Münster: Waxmann.

Sellnow-Richmond, S., Spence, P. R., \& Bevins, C. (2015). Social Media and Collaboration: The Wiki's Effectiveness as a Classroom Tool. Kentucky Journal of Communication, 34, 4-15.

Selting, M., Auer, P., Barth-Weingarten, D., Bergmann, J., Bergmann, P., Birkner, K., ... Uhmann, S. (2009). Gesprächsanalytisches Transkriptionssystem 2 (GAT 2). Gesprächsforschung Online-Zeitschrift Zur Verbalen Interaktion, 10, 353-402.

Sowe, S. K., \& Stamelos, I. (2007). Involving Software Engineering Students in Open Source Software Projects: Experiences from a Pilot Study. Journal of Information Systems Education, $18,425-436$.

Steffens, Y., Schmitt, I. L., \& Aßmann, S. (2018). Mediennutzung Studierender: Über den Umgang mit Medien in hochschulischen Kontexten. Systematisches Review nationaler und internationaler Studien zur Mediennutzung Studierender. https://doi.org/10.13154/rub.106.95

Steinhardt, I. (2018). Open Science-Forschung und qualitative Methoden - fünf Ebenen der Reflexion. MedienPädagogik: Zeitschrift für Theorie und Praxis der Medienbildung, 32, 122-138.

Steinhardt, I. (2019). Systematic literature review of "Teaching Open Science". Blogpost, https://sozmethode.hypotheses.org/839.

Teiwes-Kügler, C., \& Lange-Vester, A. (2018). Das Konzept der Habitus-Hermeneutik in der typenbildenden Milieuforschung. In S. Müller \& J. Zimmermann (Eds.), Milieu - Revisited: Forschungsstrategien der qualitativen Milieuanalyse (pp. 113-155). Wiesbaden: Springer.

Toelch, U., \& Ostwald, D. (2018). Digital open science—Teaching digital tools for reproducible and transparent research. PLOS Biology, 16, e2006022.

van Deursen, A. J., \& van Dijk, J. A. (2019). The first-level digital divide shifts from inequalities in physical access to inequalities in material access. New Media \& Society, 21, 354-375.

Veja, C., Sticht, K., Schindler, C., \& Kminek, H. (2017). SMW Based VRE for Addressing MultiLayered Data Analysis: The Use Case of Classroom Interaction Interpretation. Proceedings of the 13th International Symposium on Open Collaboration, 10:1-10:12.

Weller, M. (2018). Navigating the Open Educational Practice Landscape. Irish Journal of Technology Enhanced Learning, 3, 56-61. 